\title{
AN ACCOUNT
}

OF A

\section{LARGE DERMOID CYST FOUND IN THE ABDOMEN OF A MAN.}

\author{
BY \\ WILLIAM MILLER ORD, M.D., \\ PHYSICIAN TO, AND LECTURER ON MEDICINR AT, ST. THOMAS's \\ HOSPITAL, \\ AND \\ CHARLES BRODIE SEWELL, M.D.
}

(Received October 11th-Read October $28 \mathrm{th}, 1879$.

THE tumour now exhibited was removed post mortem from the abdomen of a gentleman who was during life under the care of Dr. Sewell. On March 8th, 1879, Dr. Sewell received from him a note saying that he had a carbuncular boil " on the old spot," and would be glad to be seen. The patient was a strong and vigorous man, aged 28, greatly given to hunting. The" old spot" was the buttock, and the inconvenience in riding produced by a boil in such a place was, in fact, the main reason for his seeking medical aid, the boil having been much irritated by a hard day's hunting. Dr. Sewell found the patient in bed, and being struck by a change in his appearance-for he was well known to him-and parvOL. LXIII. 
ticularly by some puffiness of the face, he made a general examination, in the course of which he found the abdomen large and fluctuating, evidently containing fluid. The urine was normal, the fæces hard and light in colour.

It seemed to Dr. Sewell a strange circumstance that this young man, so devoted to hunting that subsequently during an operation he said, "Go on, don't mind me, I'll think about hunting, and I shan't feel," who up to the very day of his sending for the doctor was active and cheerful, and who only expected that he had a boil, should thus keep his bed, and should not seem to have a wish to leave it, without having had one word of warning of danger, or having been put under any depressing treatment. Dr. Sewell considered it a curious indication of the effect of gradually advancing disease upon a generally healthy constitution; and the end, as Dr. Sewell remarked, coincided strangely with the beginning, for he was patient and even cheerful to the last, excepting when in unbearable agony.

The distribution of the fluid was not quite clear, for although the general appearance was that of ascites, there was permanent resonance in the left flank and across the abdomen above the umbilicus, with dulness above, these points not changing with change of position of the body. The recti muscles were widely separated along the median line, and the liver was much pushed up, the patient being conscious of some shortness of breathing. This, indeed, he remembered to have felt of late, and it also occurred to him that he had become a little unwieldy on horseback, but he had simply thought that he was getting too stout and was out of condition. There was no odema of the legs. The separation of the recti was considerable, and in view of the prevention of its increase a consultation was held between Dr. Sewell, Mr. Henry Smith, and Dr. Ord. It was then resolved that the abdomen should be tapped, and a trocar of moderate size was entered in the median line a little below the umbilicus, a point at which the absence of intestine had been ascertained. 
About two pints of fluid, looking like very well made pea soup, were drawn off, but with difficulty, the stuff becoming much inspissated and finally ceasing to flow, although the swelling was scarcely at all reduced. The fluid speedily solidified to the consistence of a pomatum, but without odour. It had an acid reaction. When melted and examined under the microscope it showed only hairs and soft epithelial scales, very few of which had nuclei. There were no hooklets of hydatids and no crystals.

Within three hours after the operation symptoms of acute peritonitis set in, and the patient died on the fifth day.

An examination of the body was made on the following day, when a large cyst was found, now chiefly filled with solid matter, occupying a great part of the abdominal cavity. The cyst lay in the back of the abdomen, and appeared from its position to be retro-peritoneal in its origin. It was firmly united to the bladder and rectum, which seemed incorporated in its walls, and also by old adhesions.to bands of both large and small intestines at various parts of its anterior surface. Besides this, general peritonitis existed, and had produced numerous fresh adhesions, particularly in the neighbourhood of the track of the trocar. The abdominal and thoracic viscera, apart from the adhesions mentioned, were normal in their structure, and the external genital organs were natural. The cyst was removed entire with the rectum, bladder, ureters, kidneys, and portions of intestine attached. When these were as far as possible removed, the bladder and part of rectum being left, it weighed $14 \frac{1}{2}$ pounds. In shape it resembled a flattened pear, or a uterus with rounded angles, the smaller end directed downwards into the space between bladder and rectum. Its length was 13 inches, its breadth 10 at the greatest, $4 \frac{1}{2}$ at the lower end, and its depth from behind forwards from 4 to 8 inches. The genito-urinary organs were, much adherent to it; they were also in various ways 
pushed out of their proper positions, but no abnormalities could be discovered. The orifice made by the trocar was visible and patulous. When the tumour was placed under water for examination fine pale hairs were seen projecting through the orifice from within. The contents of the cyst were then evacuated and had a strong rancid odour, which adhered most obstinately to the hands for many hours. They were in part a pulpy fat, mixed with abundance of hairs, in part a solid mass of the consistence of soap, having hairs imbedded. Specimens of the hair and of the fat are exhibited. The walls of the cyst were about the sixteenth of an inch in thickness, and were not elastic. Over a large area at one end of the tumour they presented, after removal of the adhering tissues, just the appearance of the corium of skin when viewed from its inner surface; they were mottled with gland-like patches, and reticulated with vessels and lymphatics. When subsequently the cyst was carefully emptied, cleansed, and distended, abundance of hairs were seen projecting from the wall into the cavity. Microscopic sections of the cyst-wall showed a structure identical with that of skin; that is to say, there could be seen epidermic and dermic layers, the former lining the cavity, hair sacs, in some cases containing hairs, and very large sebaceous glands, but no traces of sudoriparous glands. These were all much flattened or oblique to the surface. There were no regular papillæ. Regular papillæ could not be expected to exist in an envelope so enormously distended as was the wall of this cyst. But the sections for the microscope are irregularly studded with projections of the derm into the epidermis, having the appearance of distorted papillæ.

The contents of the cyst were examined by Dr. Bernays, who found them to consist almost entirely of fatnamely, of 99.75 per cent. of fatty acids. The rancid odour had led us to suppose that the constituents of sweat must enter into the composition of this matter. But Dr. Bernays cannot detect a trace of butyric acid or sweat 
products. This observation accords with the absence of sudoriparous glands from the walls of the sac. ${ }^{1}$

The specimen is very remarkable and rare in respect of its being a dermoid cyst developed in the abdomen of a man, in close structural relation with the bladder and rectum, and as regards its size it is probable unique.

One instance of a dermoid cyst occupying such a position is recorded by Dr. Wilks and Mr. Curling. In the 'Pathological Transactions,' vol. xiii, p. 148, Dr Wilks describes "some fat removed during life from a cyst near the bladder." The patient was a man, aged 21, who had experienced for twelve months increasing difficulty in urination. Mr. Pretty, of Fressingfield, having found a fluctuating tumour projecting into the rectum and pressing on the bladder punctured it through the rectum and evacuated two pints of oily matter, which became solid in cooling. Dr. Wilks, examining the fat, referred it to "one of those dermoid cysts which are occasionally found in various parts of the body as congenital growths. In the 20th volume of the same 'Transactions,' at page 238, Mr. Curling relates how the same man came under his care

1 A report of a further examination of the fat by Dr. Bernays is appended :

"Brownish soft mass, with odour of perspiration, containing hairs. Very little soluble in water.

“Free acid smelling of impure butyric acid . . 0.06 per cent.

“Actual gravity at $38^{\circ} \mathrm{C}$. . . . . . . 0 08855 "

"It saponifies with the greatest ease, showing presence of free fatty acids, which amount to no less than 98.4 per cent.

“The fatty acids are chiefly oleic and palmitic, although some olein or palmitin is distiuctly present, as the actual glycerin obtainable was 0.45 per cent.

“ Total oleic acid, as calculated from lead salt, 56.64 per cent.

"Trace of salt.

“Details.-Melting point at . . . . $\quad 32^{\circ} \mathrm{C}$.

“Sp. gr. at $38^{\circ} \mathrm{C}$. . . . . . . 0.8855

" Fixed fatty acids . . . . . 9844

"Volatile . . . . . . . . 006

$98 \cdot 46$

“Oleic acid . . . . . $\quad . \quad 5664$

"Glycerin . . . . . . . 0 0.45" 
eight years later, with symptoms of stone in the bladder, how he removed by lithotomy an oval flat stone composed of mixed phosphates, and how this stone on section proved to be formed round a nucleus of short dark hairs, corresponding under the microscope with human hairs. Mr. Curling also detected in front of the rectum, and rather to the right side, an induration, which he supposed was the remains of the contracted cyst.

Lebert ('Anatomie Pathologique Générale'' vol. i, p. 256, 1857-61) ; gives ten cases in which non-ovarian dermoid cysts containing fat and hair were found " dans les parties profondes $\mathrm{du}$ corps." This occurs among 188 dermoid cysts, 59 non-ovarian, 129 ovarian. Of the 10, 2 were in thorax, 2 near liver, 2 in mesentery, 2 near uterus, 1 between uterus and bladder, 1 between uterus and rectum. The sex is mentioned in 8 cases, only one of which was a male.

It is obvious, therefore, that the occurrence of such cysts in the male, though exceedingly rare, is not unknown. The position between the bladder and rectum appears to be not uncommon in women, for besides Lebert's cases, Blackman, in the 'American Journal of Medical Science' for January, 1869, records some, and is quoted by Mr. Curling in the paper above referred to. So far we have been dealing only with cysts containing fat and hair, but cysts containing teeth are more abundant in the body. Lebert quotes 11 cases of the kind. And, again, the non-ovarian cysts, in which other tissues and organs, or even nearly all the anatomical elements of a fœtus, are developed, must be ranked with piliferous cysts when we are endeavouring to trace their origin.

When such dermoid cysts are formed in the ovary it is not difficult to understand that the reproductive power resident under certain circumstances in Graafian follicles and ovum may have been set prematurely into operation. $\mathrm{Mr}$. Savory, indeed, suggests that this is an extreme instance of the phenomena called parthenogenesis, exhibited regularly among invertebrata, as, for instance, in the Aphis. 
According to this view the impregnation which has resulted in the formation of one individual leaves developmental force in excess, producing a second ovum within that individual, which may go one or many degrees toward the formation of another. Lebert's theory of "hétérotopie plastique" can be readily accommodated to Mr. Savory's suggestions, for it expresses the result in terms which do not explain the cause. "Beaucoup de tissus simples ou composés, et des organes plus complexes même, peuvent se former de toutes pièces dans les parties du corps où à l'état normal on ne les rencontre point." But it must be remembered that parthenogenesis is an orderly and regularly recurrent phenomenon in certain invertebrates, while the productions consistent with it in man are very rare. Putting aside, therefore, the idea of straying development in a Graafian follicle as inapplicable to the explanation of bud-growths in the human male, we may examine one or two modes in which they may come about.

1. The idea of "fœtal inclusion"-of a second less perfect individual being embraced within the developmental area of a perfect individual. This would apply very plausibly to Velpeau's case, in which a congenital cyst containing a small fœtus was removed from the scrotum of an adult.

2. The idea of "developmental inclusion," where during development parts belonging to one surface or apparatus become by some accident separated from their proper belongings and implanted in a wrong position. The somewhat common occurrence of dermoid cysts about the head and neck is most probably attributable to a process of this kind. In these parts, central raphæ and lateral fissures are often imperfectly closed; the fusion of opposing inverted surfaces is imperfectly performed. Then a fusion at the surface, associated with failure of fusion beneath, causes the formation of a cavity lined by cutaneous elements, which, growing and distended by the products of its walls, becomes a dermoid cyst. Sir James Paget has, as we all know, given much attention 
to the results following from imperfect closure of branchial fissures associated with errors of development in the structures related with them. Remak, in 1854, suggested the idea of the origin of cysts in the neck from faulty branchial sutures. Cresset more recently had in a small but very suggestive treatise, 'Sur l'appareil branchial des vertébrés,' worked out this idea as applicable to dermoid cysts in the head and neck. And in last year's ' Pathological Transactions,' Mr. Wagstaffe has collected a large number of instances of dermoid cysts developing not only at the outer angle of the orbit or beneath the tongue, but at other points where fissures run. Of these he enumerates,twenty-four, and describes in particular dermoid cysts distinctly connected by pedicles with the frontomaxillary, lacrymo-maxillary, and fronto-malar clefts respectively.

3. The idea of aberrant development. There are deformities to which the body is subject arising out of the persistence of embryonic structures which should in the natural way disappear or undergo complete remodelling. Such deformities are most common in the genito-urinary organs, where out of a number of parts seen in early embryonic life certain groups grow to constitute the organs of one or other sex, while others disappear or remain rudimentary. Occasionally, we find that organs which should have disappeared persist, sometimes in association with perfect, sometimes with imperfect, development of other parts or organs; a male apparatus simulates a female or the reverse. Applying this idea to a dermoid cyst growing in the abdomen of a man in propinquity to the posterior aspect of the neck of the bladder, we may be reminded that the ovary and testes arise in a common blastema, though each as it grows is brought into communication with a different excretory tube. If any part of this blastema fail during development to be brought into its proper system by means of the proper communication-as occasionally we may see happen to the entire testis-the part so left out, having no 
relations to guide it, may be readily conceived as proceeding to irregular development, and in this case its destiny being either to become ovary or testis may take on ovarian ways and develop dermoid cyst as an ovary might.

If in such a case as the present "developmental inclusion were the cause, we should have expected the tumour to be related with the abdominal walls. But it is clearly related with the genito-urinary organs, and we cannot see our way to suggesting how any developmental inclusion could fix a cyst in such a position. On the other hand, we have been unable to find any structural aberration in the genito-urinary organs. We are, therefore, left between fotal inclusion and aberrant development, with an inclination to the latter, founded upon consideration of corresponding ovarian tumours. 